DOI: 10.14526/2070-4798-2019-14-4-111-118

\title{
Interaction of physical and mental factors in the formation of emotional well-being as a condition for the development of preschoolers' personality
}

\author{
Marina Yu. Stozharova*, Irina O. Kuznetsova \\ Ulyanov State Pedagogical University \\ Ulyanovsk, Russia \\ ORCID: 00oo-0oo2-6289-3196, stogmarin@mail.ru \\ ORCID: oooo-ooo1-5212-6105,opaleva_irina@mail.ru
}

\begin{abstract}
In this article, the authors prove the mutual influence of physical and mental factors in formation of preschoolers' emotional well-being. Introduction. Authors point out that a child should be able to express his/her feelings and emotions, understand the causes of emotional states, as well as the emotional background of other people. it will help him/her successfully interact with the surrounding world. Materials and methods. The authors refer to the history of the issue, noting the causes of emotional reactions: the physiological needs, as well as the need for communication. Emphasize the relationship and interaction of affective and cognitive processes; in addition, emotions determine the type of motivation and behavioral reactions. Considering the concept of "emotional well-being" the authors refer to the concept of "health" in general. Results. Authors emphasize the need to preserve and promote the physical and mental health of children. Effective learning depends on the emotional state of the child, his disposition to the environmental conditions. It is determined that emotional states underline allround development of preschooler's personality. The authors do not focus only on natural affects, but also on developing a child's intellectual, moral and aesthetic feelings. Conclusion. The importance of the educational environment and certain pedagogical conditions in development of personal and emotional characteristics is proved.

Keywords: emotional sphere, preschoolers' emotional well-being, emotional characteristics, emotional development of preschool children, mental development, physical development.
\end{abstract}

For citations: Marina Yu. Stozharova*, Irina O. Kuznetsova Interaction of physical and mental factors in the formation of emotional well-being as a condition for the development of preschoolers' personality. Russian Journal of Physical Education and Sport. 2019; 14(4): 94-99. DOI: 10.14526/2070-4798-2019-144-111-118.

\section{INTRODUCTION}

The problem of children emotional development was deeply considered and studied by a number of scientists. Zaporozhets, A. V., Lisina M. I., Repina T. A. has pointed out the relationship of emotional and communicative development. Zaporozhets A.V., Neverovich Ya. Z. studied the phenomenon of emotions anticipation, Strelkova L. P. - the development of empathy; Gordeeva O.V.-the development of the emotions language in children. Vygotsky L. S., W. James, K. Izard, M. Hoffman, E. Erickson noted the importance of emotions in the personal development and adaptation of children in society.

A favorable psychological climate both in the family and in the social environment is an important condition for the formation of the preschool children personality. Physical and emotional stress affects the relationship of people: men and women (unwillingness to build a harmonious relationship), parents and children (family disharmony), teachers and students (the predominance of authoritarian communication style). Stressful states of surrounding adults affect the emotional background of the child.

The Federal state educational standard defines the principles of preschool education, one of which is the promotion and cooperation of children and adults, the recognition of the child as a fullfledged participant in educational relations. One of the main tasks of the FSES of preschool education is to protect and strengthen the physical and mental health of children, including their emotional wellbeing. This task shows that psychologists, teachers, specialists, and parents should combine their efforts to preserve the physical and mental health of the child, to ensure emotional comfort [13, C. 3].

Teachers of pre-school educational 
organizations need to support parents in matters of education and upbringing, as well as the formation of their emotional well-being. We have formulated the problem of our research: what are the conditions for organizing activities in the educational space and the family that contribute to the successful development of the preschool age child emotional sphere. It is necessary to create such pedagogical conditions that will contribute to the interaction and communication of the child with others, the formation of adequate self-esteem, the ability to restore physical and mental resources that will allow the child to be in harmony with themselves and the world around them. The aim of the study is to study in detail the approaches in the field of emotional development and personality development of preschool children. Based on the objectives of the study identified the following objectives: 1 ) to reveal theoretical foundations for the problem of physical and psychological factors interaction in preschool children emotional development; 2) to test the feasibility of this approach in the pedagogical experiment, which will be developing and testing a programme to promote emotional well-being of preschool children.

\section{MATERIALS AND METHODS}

The complex definition of the phenomenon "emotion" includes physiological, expressive and empirical components. Emotion arises as a result of neurophysiological processes that can be caused by both endogenous and exogenous factors. When an emotion arises in response to a mental image or representation, it is possible to think about the formed connection of thought and feeling, about the affective-cognitive structure.

Studying the emotional sphere of the person, it is necessary to focus on the origins of emotional reactions and manifestations. Undoubtedly, one of the reasons for the emergence of human emotions was the need to ensure a social connection between mother and child. An adult is necessary for the child to survive, as it is the carrier of physiological, social and cognitive skills. In addition, it has been proven that for physical health and emotional well-being, a child needs parental love and care. Another reason for emotions was the need for communication between mother and child, as well as adults. Studies have shown that before the child begins to understand the speech addressed to him and before the formation of his own speech, he is able to inform others about his internal state using a certain set of signals [8, P. 112].

Studying the nature of emotions, scientists have determined that a child from birth has some unconditional affective reactions (born with the ability to feel). During the first year of life, the baby expresses its needs and feelings by facial expressions, intonation, certain movements that are quite understandable to the person who cares about it. In the preschool period, emotions go through a path of tremendous development, acquiring more and more rich content and more complex forms of manifestation in the process of interaction with society.

Considering emotions as functions of cognitive processes, we have drawn attention to a theory based on three acts: perception (or elementary understanding) - evaluation-emotion. A person, getting into certain conditions, perceives and evaluates the situation. Thus, it has an effect on him and causes specific emotional reactions. Assessment is an immediate, intuitive act that is not associated with meditation. Intuitive assessment of the situation generates a tendency to action. It is experienced as an emotion and is expressed by various somatic changes. A certain emotional response tends to be permanent, meaning that an object or situation that has been evaluated and received a specific emotional response subsequently elicits the same evaluation and emotion.

Theoretical developments of the cognitive and social-cognitive directions give priority to cognitive processes in the process of emotions, without denying the motivational and adaptive role of emotions. It is also noted that cognitive processes serve as a necessary link in the chain of events that activate emotion. But an emotion cannot be considered only as an action performed in response to a stimulating event or situation; it is also the stimulus or cause of our actions.

In the studies of domestic psychologists (L. S. Vygotsky, A. N. Leontiev, D. B. Elkonin), the value of emotions in the life of a child is considered 
from other positions. The authors do not focus on natural affects, but on the development of the child's intellectual, moral and aesthetic feelings. The formation of higher human feelings occurs in the process of social values assimilation, requirements, norms and ideals. They in favorable conditions become the internal property of the individual. As a result, the child begins to evaluate the world around him emotionally, notes attractive and unattractive objects, good and bad actions, etc. thus, feelings play an important role not only in the energy supply, but also in the structuring of activity, in the formation of its motives and in determining its goals [5, P. 67].

Emotions have become one of the humanity hallmarks. We see that emotions are necessary for human survival and well-being. Our ability to feel and express our feelings with the utmost clarity and perseverance directly affects our viability. Important is the ability to empathize with other people's emotions, the ability to empathy, as well as the ability to express an emotion in words, to tell about it. In addition, emotions provide the type of motivation, behavioral trends and variability of behavior, without which a person is not able to successfully interact with the world and adapt to new conditions.

In proof of the above argument, it should be noted that the emotion motivates the individual, mobilizes his energy, and this energy is felt by the subject as a prerequisite for the action. Emotion activates the mental and physical activity of the individual, as well as regulates or, in other words, filters our perception. For example, happiness makes a person feel touched by the most ordinary things. A specific emotion encourages a person to a specific activity, to specific behavioral reactions. It indicates that the emotion organizes thinking and activity. Emotions affect our feelings, how we perceive information, so emotional States have a direct impact on the quality of the performed activity - game, educational, labor, etc. Effectiveness of training depends more on how the child emotionally relates to the proposed task, to the teacher, to the cognitive process as a whole, how he experiences his successes and failures. Such emotional manifestations have an impact not only on the level of intellectual development, but also on mental activity, and even on the creative abilities of the child. Of course, the development of creative potential contributes to the inclusion of children in various types of artistic activities [10, P. 298].

Emotions are of paramount importance for the education of the individual and for instilling in it socially significant features. A morally educated person is not only one who knows the rules and regulations of behavior, but also one who has knowledge merged with feeling, forming the beliefs that make up the core of the human personality. High intellectual and aesthetic feelings can inspire a child to do good deeds, noble deeds, and achieve new goals. That is why teachers of preschool education and parents need to develop higher feelings, creating favorable living conditions for children.

At this stage of the study we identified a set of methods: theoretical analysis of psychological and pedagogical literature on the problem of preschool children emotional development; monitoring of preschoolers emotional sphere formation; included observation; pedagogical experiment; questionnaire; statistical data processing and others.

\section{RESULTS AND DISCUSSION}

The main result of the psychological and pedagogical literature theoretical study is to determine and justify the importance of the physical and mental factors interaction in the emotional development of preschoolers. Studying the emotional sphere of the individual, emotional wellbeing, we can not separate these concepts from the concept of health in general, because it is a healthy person can meet the high requirements of modern society.

The most important component of health culture is systematic physical training and sports. They are considered by modern psychological and pedagogical science as a special type of activity that contributes to the education and development of the best physical, moral and mental qualities. In preschool educational organizations, children are introduced to the technical elements of various sports (swimming, skating, skiing), master the skills of cycling, learn some sports (badminton, basketball, towns). Health care includes physical activity, walking in the fresh air, hardening, attention to 
the inner world of the child, to his feelings and experiences, interests and hobbies, abilities and knowledge, his attitude to himself, peers, the world around him, family and social events [12, P. 155].

In our research we pay special attention to the relationship between physical and mental factors in the emotional development of children. Many domestic and modern researchers point to the unity of mental and physical health in general: G. V. Morozov, M. S. Lebedinsky, F. V. Bassin, G. I. Tsaregorodtsev, G. K. Shingarov, V. V. Nikolaeva, and others. We note that in pre-school educational organizations the general task of child development is artificially divided into two components. The activities of physical education instructors and educators are usually aimed at the physical development of preschoolers (development of the musculoskeletal system, the main motor qualities: dexterity, flexibility, coordination of movements, etc.). The second component-neuropsychic, usually separated from the first and is accompanied by psychologists, speech therapists, narrow specialists. Motor activity largely determines the development of the body, nervous system and psyche, along with the genetic factor and the influence of sensory different-modal information.

The role of heredity (factor) in the formation of emotional experiences, emotional expression and emotional behavior individual characteristics is noted in the research of foreign scientists. Children from 6 months to 2 years were in the same social conditions, but had significant differences in emotional manifestations and in the level of emotional thresholds. The role of genetic prerequisites in determining personal and emotional characteristics is also shown. The fact of monozygous twins psychological characteristics similarity is known, even when they grew up and were brought up in different conditions.

Currently, children's health problems are hypodynamia (violation of the musculoskeletal system functions, blood circulation, breathing, digestion); children's stress (nervous disorders due to the adverse psychological climate in the family, excessive noise and hyperactivity in the children's team); anxiety (lack of emotional support in the kindergarten and family). However, it should be noted that deviations in physical health are risk factors for mental development of the individual. In the absence of proper timely attention to such deviations, they are aggravated, affecting primarily the personal sphere and leading to a persistent violation of children adaptive capabilities, the manifestation of pronounced shortcomings in their behavior, communication activities. According To L. S. Vygotsky, a child with somatic diseases has a constant social situation of development, since "every bodily defect not only changes a person's attitude to the world, but, above all, affects relations with people"[5, P.68]. In connection with negative trends, it is necessary to pay special attention to the upbringing of a physically healthy and socially adapted child, ensuring his emotional well-being, as well as the formation of responsibility for their health, it is also important to promote the development of a culture of health of preschool teachers.

In addition, we note the importance of training, education and other environmental factors in the formation of personal and emotional characteristics. The emotional characteristics of the individual are partly due to the peculiarities of his social experience acquired in the early period of his development. The social development of children can only be carried out in emotional contact with adults. L. A. Abrahamyan notes that the ideals of adults, the system of requirements for the child, taking into account its individual characteristics largely determine the content, strength and depth of its emotional manifestations. The child learns very early the system of relations of the environment in which he lives. Directly perceiving the emotional atmosphere of the family, imitating adults, the child adopts their value orientations, attitude to people, the world as a whole. Therefore, it is necessary to take into account the sensitive period of emotional formation of the personality. It is during preschool childhood that emotional neoplasms and achievements are formed, and it is possible to recognize emotions. The mechanism of emotional anticipation begins to function, experiences become conscious, their content becomes more complicated $[7$, P. 174].

Since childhood, the emotional world is 
mediated by meanings and a system of interpersonal relations; the process of their individualization is carried out during the formation of personal existence and creative self-activity model. A child of preschool age has difficulties identifying emotions. It is due to poor emotional experience. Emotional experience is necessary to achieve an understanding of emotional phenomena. In modern research, it is noted that inadequate or insufficient experience of emotional experiences leads to underdevelopment of "affective circuits", to difficulties in understanding and verbalization of their own emotions, prevents interaction with others and understanding their emotional states.

Exploring the process of higher human feelings formation, we note the relationship between the emotional and intellectual spheres of personality, as well as the influence of emotions on the physical and mental development of the child. In other words, emotional development is an important condition that ensures the full development of the individual. To maintain the tone of the nervous system and mental activity, the child needs to be outdoors, perform physical exercises, play outdoor games. It has a positive impact on his physical and spiritual development. Despite the fact that children differ in types of mobility and characteristics of character, it is advisable to form preschoolers interest in sports, the desire to participate in games, to be active in the classroom. Physically weakened children are subject to rapid fatigue, their emotional tone and mood are reduced. It negatively affects the nature of mental performance of children.

Defining the role of educational organizations in the formation of a fully developed personality, I. A. Baeva notes that the educational environment is a psychological and pedagogical reality containing specially organized conditions for the personality formation, as well as opportunities for development, included in the social and spatialsubject environment, the psychological essence of which is a set of activity-communicative acts and relationships of participants in the educational process. Fixation of this reality is possible through the system of the subjects relations participating in it [1, P. 36].

\section{CONCLUSION}

Having studied the theoretical foundations of preschool children personality emotional sphere development, the influence of emotions on cognitive activity, the type of motivation, forms of behavior, we focus on the importance of the emotional wellbeing formation in an educational organization. We emphasize the close connection of physical and mental factors in the formation of emotional well-being, based on the main task of training and education - the preservation and strengthening of preschool children physical and mental health, ensuring their emotional comfort, which once again shows theimportance of improving the health culture of the educational space subjects. In a favorable educational environment, the child is able to actively assimilate the norms and ideals of modern society, successfully interact in the children's team, to show creative and cognitive activity. Thus, we consider it appropriate to create favorable conditions for the formation of the individual emotional sphere in the educational space. The activities of children are filled with emotional experiences. These experiences should not remain without the attention and control of experienced professionals. In connection with the above argument, it is necessary to provide teachers of preschool education with an effective program for the formation of preschool children emotional wellbeing. In this we find the practical significance of our further research.

\section{REFERENCES}

1. Baeva I.A., Vikhristyuk O.V., Gayazova L.A. Bezopasnost' obrazovatel'noj sredy: psihologicheskaya ocenka I soprovozhdenie: sdornik nauchnyh statej [Safety of the educational environment: psychological assessment and support: collection of scientific articles]. Moscow: MGPPU. 2013: 304 (In Russ.).

2. Valkina O.N., Kodolova F.M., Funina E.E. Game activity as a factor in introducing children and adolescents to systematic physical exercises. Pedagogiko-psihologicheskie I medicobiologicheskie problemy fizicheskoj kul'tury I sporta = Pedagogico-psychological and medicobiological problems of physical culture and sports. 2016; 1(38): 129-136. DOI: 10.14526/01_1111_88 (In Russ., In Engl.)

3. Vedyaev F.P. Mozg, emocii, zdorov'e 
[Brain, emotions, health]. M.: Knowledge. 2015: 185 (In Russ.).

4. Vilyunas V.K. Psihologiyz emocional'nyh yavlenij [Psychology of emotional phenomena]. Moscow: Mosk publishing House. UN-TA. 2011: 143 (In Russ.).

5. Vygotsky L.S. Psihologiya razvitiya rebenka [Psychology of child development]. M.: Sense, Eksmo. 2005: 512 (In Russ.).

6. Gippenreiter Y.B. Razvivaem emocional'nyj intellekt. Vmeste perezhivaem $I$ igraem [Develop emotional intelligence. We experience and play together]. M.: AST. 2014: 96 (In Russ.).

7. Izard K.E. Emocii cheloveka [Human Emotions]. SPb.: Peter. 2000: 440 (In Russ.).

8. Izotova E.I. Zakonomernosti I invarianty emocional'nogo razvitiya detej I podrostkov [Regularities and invariants of emotional development of children and teenagers]. M.: Moscow State Pedagogical University. 2014: 236 (In Russ.).

9. Lapteva Yu.A., Morozova I.S. Development of the preschool age child emotional sphere. Vestnik Kemerovskogo gosudarstvennogo universiteta. 2016; 3: 51-55 (In Russ.).

10. Razenkova N. E. Theoretical aspects of emotional and expressive development of the individual. Sibirskij pedagogicheskij zhurnal. 2010; 6: 296-304 (In Russ.).

11. Rapoport G.N., Hertz A.G. Biologicheskij I iskustvennyj razum. Chast' 1. Soznanie, myshlenie I emocii [Biological and artificial intelligence. Part 1. Consciousness, thinking, and emotions]. M.: Librokom. 2011: 184 (In Russ.).

12. Stozharova M. Yu. Application of healthsaving technologies as a condition for the formation of the physical component of school maturity of children of senior preschool age. Pedagogikopsihologicheskie I medico-biologicheskie problemy fizicheskoj kul'tury I sporta = Pedagogicopsychological and medico-biological problems of physical culture and sports. 2016; 2: 153-162. DOI: 10.14526/01_1111_114 (In Russ., In Engl.)

13. Stozharova M.Yu., Pronina N.S., Mavrina Yu.V. Formation of bases of psychological health of children of senior preschool age. Detskij sad ot A do Ya. 2017; 2: 93-97 (In Russ.).

14. Federal State educational standard of preschool education: approved by the order of the Ministry of education and science of the Russian Federation dated October 17, 2013, No. 1155. Ministry of education and science of the Russian Federation. Moscow: 2013.

15. Shadrikov V. D. Vvedenie v psihologiyu: emocii I chuvstva [Introduction to psychology: emotions and feelings]. M.: Logos. 2017: 156 (In Russ.).

16. Goleman D., Chemiss I.C. Emotional intelligence: Issues in paradigm building. 2001: 320.

17. Mayer J., Salovey P., Caruso D. Emotional Intelligence: Theory, Findings and Implication; Psychological Inquiry. 2004; 15(3): 197-215.

18. Meadows C.M. The phenomenology or joy: An empirical investigation. Psychological Reports. N.Y. 1997: 39-54.

19. Vernic Leslie. How to find selfless joy in Me-First world. USA, First Edition, Water Brook Press. 2003: 398.

20. Wessman F.E., Ricks J.H. Mood and personality. N.Y., Holt Rinehart and Winston. 1996: 122-131.

\section{Submitted: 03.03.2019}

\section{Author's information:}

Marina Yu. Stozharova - Candidate of Pedagogics, Associate Professor, Ulyanov State Pedagogical University, Ulyanovsk, 43270o, Russia, Ulyanovsk, Square of the 1ooth anniversary of the birth of V.I. Lenin, House 4, e-mail: stogmarin@mail.ru

Irina O. Kuznetsova - Post-graduate, Ulyanov State Pedagogical University, Ulyanovsk, 4327oo, Russia, Ulyanovsk, Square of the 1ooth anniversary of the birth of V. I. Lenin, House 4, e-mail: opaleva irina@mail.ru 